\title{
Development of a Rapid HPLC-UV Method for Analysis of Menaquinone-7 in Soy Nutraceutical
}

\section{Rishipal S, Alka P, Mojeer H and Bibhu Prasad P*}

Microbial and Pharmaceutical Biotechnology Laboratory, Centre for Advanced Research in Pharmaceutical Sciences, India

*Corresponding author: Bibhu Prasad P, Assistant Professor (Pharmaceutical Biotechnology), Microbial and Pharmaceutical Biotechnology Laboratory, Centre for Advanced Research in Pharmaceutical Science, Faculty of Pharmacy, Jamia Hamdard, New Delhi 110062, India, Tel: +919990335013; E-mail: bibhu_panda31@rediffmail.com

Received date: October 28, 2016; Accepted date: December 21, 2016; Published date: December 26, 2016

Copyright: (C) 2016 Rishipal S, et al. This is an open-access article distributed under the terms of the Creative Commons Attribution License, which permits unrestricted use, distribution, and reproduction in any medium, provided the original author and source are credited.

\begin{abstract}
Among all fermented foods, fermented soybeans (soy nutraceutical) were found wide applications as nutraceutical due to nutritional benefit. The vitamin $\mathrm{K} 2$, menaquinone-7 (MK-7) is commonly used for preventing osteoporosis and is an important secondary metabolite of soy nutraceutical. A consistent and improved highperformance liquid chromatography (HPLC) method for determination of MK-7 in fermented soybean is developed. The analysis was achieved on Lichrospher-100, RP-C $18(5 \mu \mathrm{m})$ column with a dimension $125 \mathrm{~mm} \times 4.0 \mathrm{~mm}$, with detection at $248 \mathrm{~nm}$ using a gradient mobile phase mixture of water and methanol $(1: 1 \mathrm{v} / \mathrm{v})$ acidified to $\mathrm{pH} 3.0 \mathrm{by}$ orthophosphoric acid and acetonitrile with a flow rate of $1.2 \mathrm{~mL} \mathrm{~min}^{-1}$. Under these conditions, the analysis of MK-7 was achieved in less than $4 \mathrm{~min}$. The retention time was found to be $2.38 \mathrm{~min}$. The calibration curve for MK-7 was linear in the range of $2.5-20 \mu \mathrm{g} \mathrm{mL}^{-1}$ with $\mathrm{R}^{2}=0.9997$. The proposed method was successfully employed for quantification of the MK-7 present in soy nutraceutical.
\end{abstract}

Keywords: Menaquinone-7; Vitamin K2; Fermented soybean; HPLC-UV; Bacillus subtilis

\section{Introduction}

Menaquinone-7 (MK-7) is a vitamin K-2 analogue and plays an important role in the carboxylation of $\gamma$-glutamate residues of the osteocalcin [1-4]. The $\gamma$-carboxylated osteocalcin promotes the mineralisation of bone in osteoblasts in bone metabolism, thereby help in the prevention of osteoporosis [5,6]. High dietary MK-7 intake reduces coronary calcification and prevents cardiovascular disease [7]. The important source for MK-7 includes fermented soybeans like natto and found both in animal products and in the intestine [8,9]. There are reports on the biosynthesis of MK-7 from vitamin K1 by microorganisms [10]. Due to anti-osteoporosis activity, MK-7 incorporated into the multivitamin formulation and along with calcium and vitamin D. Therefore, analysis of MK 7 is required and urgently needed.

The chromatographic analysis of MK-7 will play an important role in establishing the quality of MK-7 containing fermented food, pharmaceuticals and its metabolism/biosynthesis. The objective of this study was to develop and validate a rapid HPLC-UV method and to investigate the concentration of the MK-7 present in nutraceutical produced under solid-state fermentation of soybean by Bacillus subtilis fermented soybeans by a newly developed high-performance liquid chromatography-UV method.

\section{Materials and Methods}

\section{Materials and microorganism}

The culture of Bacillus subtilis NCIM 2708 was obtained from National Collection of Industrial Microorganisms, National Chemical
Laboratory, Pune, Maharashtra, India. It was maintained on slants of the nutrient agar mediums at $4^{\circ} \mathrm{C}$ and sub cultured at every 30 days interval. All the chemicals and solvents used in the research procured from Merck, Mumbai, India. Microbiological media procured from HiMedia, Mumbai, India. Soybean verity SL-525 and DS-9814, collected from the Pulse Laboratory of Indian Agricultural Research Institute, New Delhi, India. The reference compound MK-7 obtained from Medley Pharmaceuticals, India.

\section{Preparation of seed culture}

Microbial suspension of Bacillus subtilis NCIM 2708 was prepared from actively growing slants in distilled sterile water. Microbial suspension was inoculated into the seed culture medium $(1 \% \mathrm{v} / \mathrm{v})$ containing soybean powder 6\% (soybean variety, SL-525), sodium chloride $0.5 \%$ and distilled water adjusted to $\mathrm{pH} 7.0$ with $0.1 \mathrm{~N} \mathrm{HCl}$ or $0.1 \mathrm{~N} \mathrm{NaOH}$ [11] and incubated at $37^{\circ} \mathrm{C}$ for $24 \mathrm{~h}$ in a shaker incubator at $180 \mathrm{rpm}$.

\section{Soy nutraceutical production}

Soybean based nutraceutical was prepared by the solid-state fermentation of soybean seeds by Bacillus subtilis NCIM 2708. Soybean seeds (variety DS-9814) were prepared for the fermentative production of MK-7 by successive procedures of washing, soaking, boiling and dehulling respectively. The prepared soybean seeds were sterilised and seed culture of B. subtilis NCIM 2708 was added at a concentration of $1 \mathrm{~mL} \mathrm{~g}^{-1}$. Fermented in a humidity incubator at $37^{\circ} \mathrm{C}$ and $75 \%$ relative humidity for $24 \mathrm{~h}$.

After solid-state fermentation, the fermented soybean seeds are kept at $4^{\circ} \mathrm{C}$ for 7 days in order to achieve the ageing process [12]. Aged fermented soybeans were autoclaved and extraction of MK-7 was carried out with different solvents. 
Page 2 of 4

\section{Extraction of MK-7 from fermented soybeans}

Fermented soybean seeds DS-9814 (5 g) were triturated by the mortar-pestle. To the fermented soybean DS-9814, $15 \mathrm{~mL}$ of different non-polar and medium polar extracting solvents i.e., propan-2-ol \& nhexane $(1: 2 \mathrm{v} / \mathrm{v})$, toluene, acetonitrile and ethanol were added and were mixed by vigorous shaking for $10 \mathrm{~min}$. The mixture was centrifuged at $3000 \mathrm{rpm}$ for $5 \mathrm{~min}$ and the organic layer was separated and concentrated up to $1 \mathrm{~mL}$. Samples obtained were filtered through $0.45 \mu \mathrm{m}$ membrane filter and were analysed by HPLC for quantification of MK-7.

\section{Preparation of standard MK-7}

Different concentrations $\left((2.5,5.0,10,20) \mu \mathrm{g} \mathrm{mL}^{-1}\right)$ of standard MK-7 were prepared in a solvent mixture of water \& acetonitrile (2:8 $\mathrm{v} / \mathrm{v})$. Standard solutions were filtered through a $0.45 \mu \mathrm{m}$ membrane filter and were analysed by the HPLC to prepare the standard plot of MK-7.

\section{Chromatographic condition and analysis of MK-7}

The extracted and standard MK-7 were analysed by quaternary HPLC system (Shimadzu Japan). The system software was class-VP equipped with Lichrospher-100, RP- $\mathrm{C}_{18}$ column with $5 \mu \mathrm{m}$ sizes and a dimension of $125 \mathrm{~mm} \times 4.0 \mathrm{~mm}$. The column temperature was kept at $25^{\circ} \mathrm{C}$. Elution of MK-7 was optimised by using different mobile phase with different flow rate under isocratic and gradient mode conditions. Detection of MK-7 was carried out by UV detector. Peaks were analysed by using software Class VP (Shimadzu, Japan). Some of the close chromatographic conditions under which the MK-7 was detected are presented below.

\section{Chromatographic condition I}

A mixture of water and methanol $(1: 1 \mathrm{v} / \mathrm{v})$ acidified to $\mathrm{pH} 3.0$ by orthophosphoric acid (A) and acetonitrile (B) with a flow rate of 1.2 $\mathrm{mL} \mathrm{min}^{-1}$ under gradient mode was used as mobile phase. The absorbance of MK-7 was detected at $248 \mathrm{~nm}$ with a gradient elution (Table 1).

\begin{tabular}{|l|l|l|l|}
\hline Events Number & Time & Solvent & $\%$ \\
\hline 1 & 0.01 & Acetonitrile & 80 \\
\hline 2 & 3.50 & Acetonitrile & 80 \\
\hline 3 & 4.50 & Acetonitrile & 100 \\
\hline 4 & 6.50 & Acetonitrile & 100 \\
\hline 5 & 10.00 & Acetonitrile & 80 \\
\hline
\end{tabular}

Table 1: The gradient time programme for chromatographic condition I.

\section{Chromatographic condition II}

Methanol (A) and Acetonitrile (B) $(1: 1 \mathrm{v} / \mathrm{v})$ with a flow rate of $1 \mathrm{~mL}$ $\min ^{-1}$ under isocratic condition was used as mobile phase with absorbance at $254 \mathrm{~nm}$.

\section{Chromatographic condition III}

Methanol (A) and water (B) $(95: 5 \mathrm{v} / \mathrm{v})$ with a flow rate of $1 \mathrm{~mL}$ $\min ^{-1}$ under the isocratic mode of elution with detection of MK-7 at $254 \mathrm{~nm}$.

\section{Results and Discussions}

\section{Chromatographic analysis of standard MK-7}

The standard MK-7 concentration of $10 \mu \mathrm{g} \mathrm{mL}-1$ eluted with different chromatographically conditions shows different $R_{t}$ and percentage elution pattern (Figures 1a-1c). Under chromatographic conditions, I the $R_{t}$ was found to be the lowest i.e., 2.3 min with $99 \%$ elution. Under the chromatographically condition, II the $\mathrm{R}_{\mathrm{t}}$ was found to be the highest i.e., $4.8 \mathrm{~min}$ with $68 \%$ elution. Under the chromatographically condition, III the $\mathrm{R}_{\mathrm{t}}$ was found to be $3.4 \mathrm{~min}$ with $90 \%$ elution. From results, it shows that gradient mode of elution resulted enhanced MK-7 elution than an isocratic mode of elution.
Further, under gradient mode, the elution time was decreased considerably in comparison to the isocratic mode. Out of chromatographically condition, I and III, condition I was better than condition III for analysis of MK-7.

\section{Linearity of analysis}

Different dilution of MK-7 $((2.5,5,10,20) \mu \mathrm{g} \mathrm{mL}-1)$ was prepared and analysed by the chromatographic condition, I. The solutions were injected in triplicate, and the regression equation was found $\mathrm{Y}$ (MK $7)=118202 \times+22026\left(R^{2}=0.9997\right)$ by plotting the peak area $(Y)$ versus the MK-7 concentration (X) expressed in $\mu \mathrm{g} \mathrm{mL} \mathrm{L}^{-1}$. The coefficient $\left(\mathrm{R}^{2}\right)$ obtained for the regression line demonstrates the excellent relationship between peak area and the concentration of MK-7. The chromatograms were represented in Figure 2.

\section{Precision of analysis of HPL chromatogram method}

The precision of the chromatographic analysis of MK-7 was observed in the form of percent relative standard deviation (\% RSD) and was estimated by measuring the repeatability of intra-day analysis on five replicate of the MK-7 solution at the highest concentration. The RSD value for peak area and retention time $\left(R_{t}, \min \right)$ was found to be 0.16 and 0.14 respectively. 

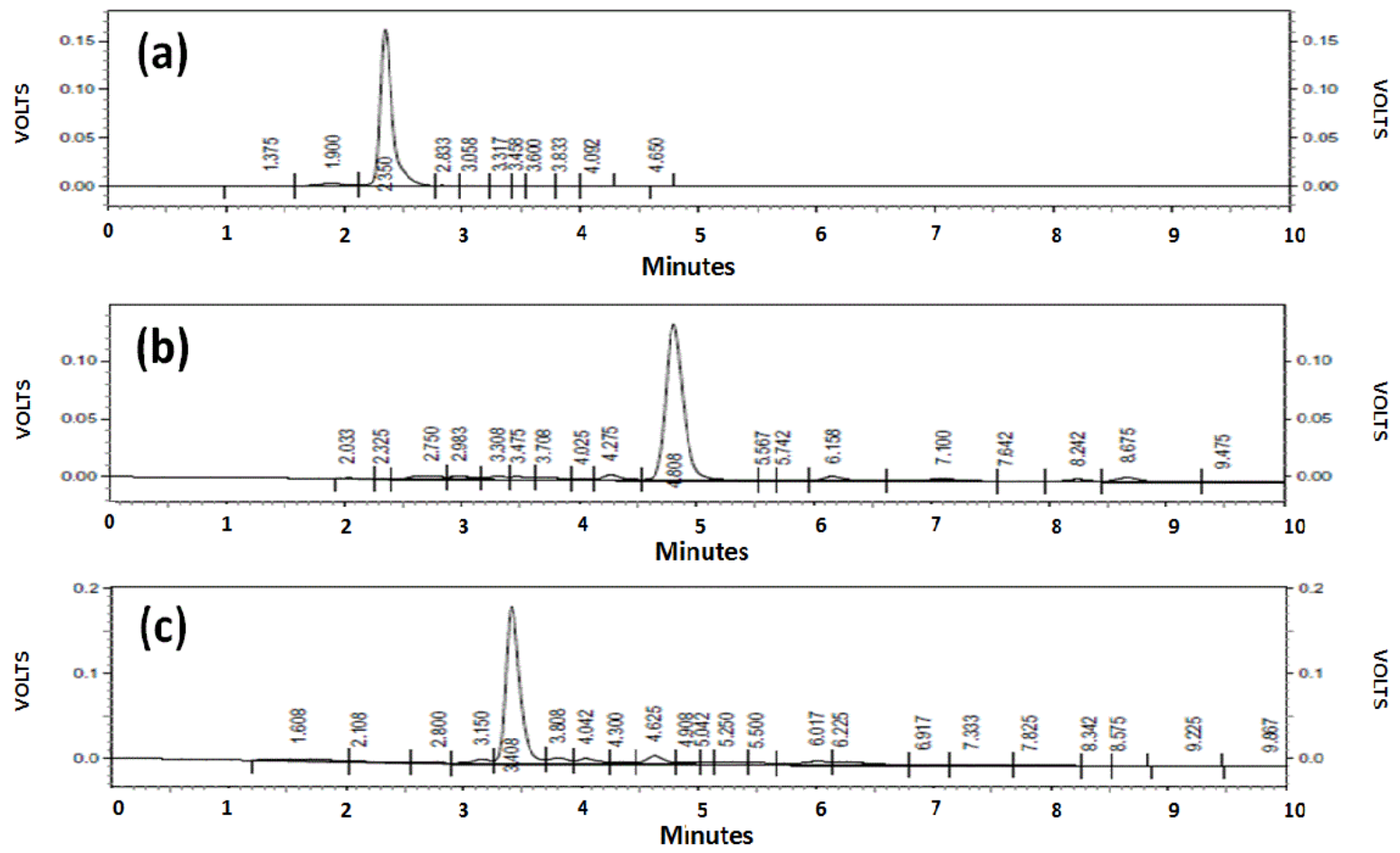

Figure 1: The chromatograms of MK-7 $\left(10 \mu \mathrm{gmL}^{-1}\right)$ eluted under chromatographic conditions I (a), chromatographic conditions II (b) and chromatographic conditions III (c)

\section{Limits of detection and quantitation of MK-7 analysis}

The Limit of Detection (LOD) and Limit of Quantitation (LOQ) of MK-7 analysis were determined by the calibration plot method [13]. LOD and LOQ were calculated by use of the equations:

$$
\mathrm{LOD}=\mathrm{C}_{\mathrm{lod}} \times \mathrm{R}_{\mathrm{vr}} / \mathrm{S}_{1}
$$

$\&$

$$
\mathrm{LOQ}=\mathrm{C}_{\mathrm{loq}} \times \mathrm{R}_{\mathrm{vr}} / \mathrm{S}_{\mathrm{l}}
$$

Where $\mathrm{C}_{\text {lod }}$ and $\mathrm{C}_{\text {loq }}$ are the coefficients for LOD and LOQ, Rvr is the residual variance of the regression, and $\mathrm{S}_{1}$ is the slope. Calculations were performed by using values of $\mathrm{C}_{\mathrm{lod}}$ and $\mathrm{C}_{\mathrm{loq}}$ of 3.3 and 10. LOD and LOQ of MK-7 were found to be $0.49 \mu \mathrm{g} \mathrm{mL}^{-1}$ and $1.499 \mu \mathrm{g} \mathrm{mL}^{-1}$ respectively.

\section{Accuracy and specificity of the HPL chromatogram analysis}

Accuracy and specificity of the chromatographic method was tested on fermented soybean seeds containing MK-7. The analysis was carried out with and without co-injection of MK-7. The MK-7 extraction from nutraceutical was carried out by successive extraction through propan-2-ol and n-hexane (1:2 v/v), toluene, acetonitrile and ethanol separately. Propan-2-ol and n-hexane extract found to be having maximum, $8.28 \mu \mathrm{g}$ of MK-7 per gram while acetonitrile extract found to contain $3.24 \mu \mathrm{g}$ of MK-7 per gram of soy nutraceutical. However, MK-7 was undetected toluene and ethanol extract [8].

The retention time for MK-7, extracted from fermented soybean seeds was increased to $2.44 \mathrm{~min}$ from $2.39 \mathrm{~min}$. The accuracy \& specificity of the analysis and extraction procedure was carried out by adding internal standard of MK-7 $\left(2.5 \mu \mathrm{g} \mathrm{mL} \mathrm{m}^{-1}\right)$ to one gram of fermented soybeans and extracted with propan-2-ol and n-hexane (1:2 $\mathrm{v} / \mathrm{v})$ shows $R_{t}$ at $2.35 \mathrm{~min}$ and concentration was found to be $11.77 \mu \mathrm{g}$ $\mathrm{g}^{-1}$ with $89.32 \%$ elution. The chromatograms of extracted MK-7 from soybean nutraceutical with and without internal standard were shown in Figure 3. In a study determination of MK-7 by HPLC was obtained by using mobile phase with a mixture of methanol and ethanol 95:5 (v/v).

The fluorescence detector was used for the analysis of MK-7 with a flow rate of $1 \mathrm{~mL}$ min- 1 and the retention time was $3.0 \mathrm{~min}$ [14]. In the present study of the analysis of MK-7 through HPLC by gradient elution program, the mobile phase was a mixture of water $(\mathrm{pH}$ adjusted to 3.0 with orthophosphoric acid) and methanol $(1: 1 \mathrm{v} / \mathrm{v})$ and acetonitrile in a ratio of $2: 8(\mathrm{v} / \mathrm{v})$ with a flow rate of $1.2 \mathrm{~mL} \mathrm{~min}^{-1}$ by using UV detector at a $\lambda_{\max }$ of $248 \mathrm{~nm}$. The benefit of this modification was that total retention time of MK-7 was decreased from 3 min to a retention time of $2.3 \mathrm{~min}$ and analysed by UV detector, which is comparatively cheaper and widely used than a fluorescence detector. 
Page 4 of 4

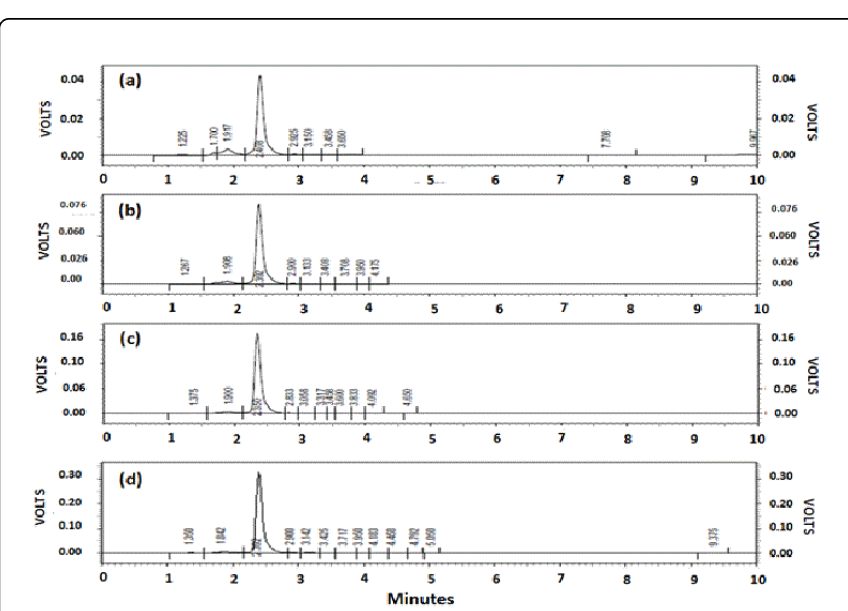

Figure 2: The chromatograms of MK-7 of concentration $2.5 \mu \mathrm{g} \mathrm{mL}^{-1}$ (a), $5 \mu \mathrm{g} \mathrm{mL} \mathrm{m}^{-1}$ (b), $10 \mu \mathrm{g} \mathrm{mL} \mathrm{m}^{-1}$ (c) and $20 \mu \mathrm{g} \mathrm{m} \mathrm{m}^{-1}$ (d) eluted under chromatographic conditions I.

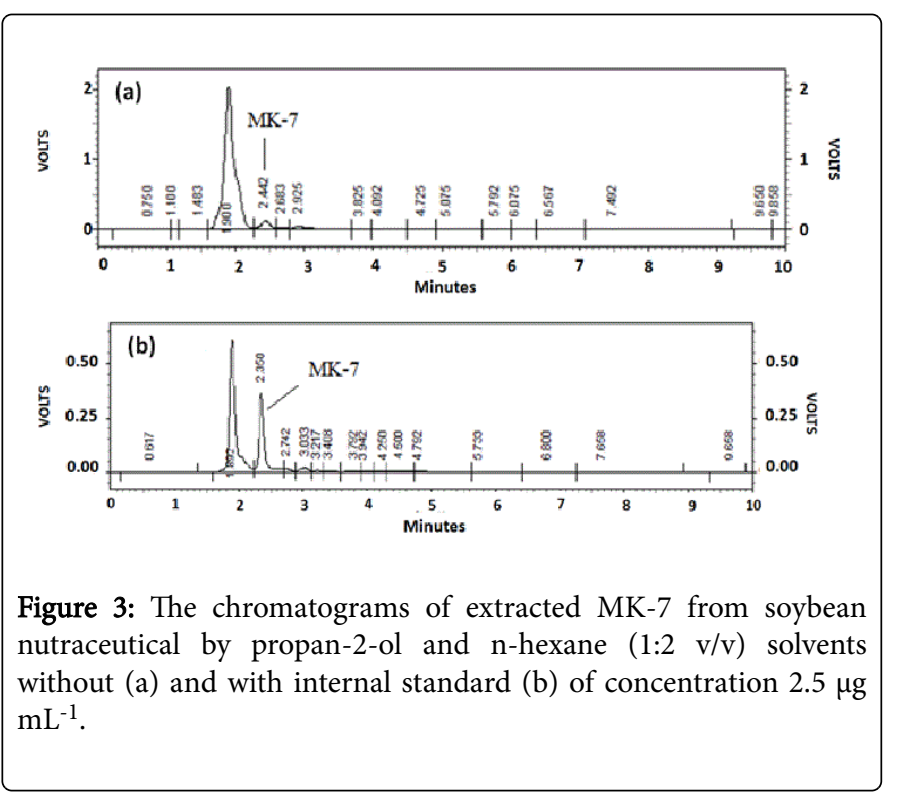

\section{Conclusion}

The newly developed gradient HPLC-UV method for analysis MK-7 in soybean nutraceutical is specific, accurate, rapid and precise. The HPLC of MK-7 achieved by UV detector under the gradient mode of elution. The peak area and MK-7 concentration show excellent correlation. Further, the highest amount of MK-7 was extracted with using a solvent mixture of propan-2-ol and $n$-hexane $(1: 2 \mathrm{v} / \mathrm{v})$ from fermented soybean. The developed method can be useful for extracting and analysing the MK-7 present in fermented soybean seeds and multivitamin formulation.

\section{Acknowledgement}

The Authors acknowledge the Department of science and technology (DST), Government of India for providing fellowship to the research scholar, Ms. Alka Puri.

\section{References}

1. Yamaguchi M, Sugimoto E, Hachiya S (2001) Stimulatory effect of menaquinone-7 (vitamin K2) on osteoblastic bone formation in vitro. Mol Cell Biochem 223: 131-137.

2. Yamaguchi M, Taguchi H, Gao YH, Igarashi A, Tsukamoto Y (1999) Effect of vitamin K2 (menaquinone-7) in fermented soybean (natto) on bone loss in ovariectomized rats. J Bone Miner Metab 1: 23-29.

3. Yamaguchi M, Uchiyama S, Tsukamoto Y (2013) Inhibitory effect of menaquinone-7 (vitamin K2) on the bone-resorbing factors-induced bone resorption in elderly female rat femoral tissues in vitro. Mol Cell Biochem 245: 115-120.

4. Tsukamoto Y, Kasai M, Kakuda H (2001) Construction of a Bacillus subtilis (natto) with high productivity of vitamin K2 (menaquinone-7) by analog resistance. Biosci Biotechnol Biochem 65: 2007-2015.

5. Schurgers J, Cranenburg E, Vermeer C (2008) Matrix Gla-protein: the calcification inhibitor in need of vitamin K. Thromb Haemost 4: 593-603.

6. Atkins G, Welldon K, Wijenayaka A, Bonewald L, Findlay D (2009) Vitamin $\mathrm{K}$ promotes mineralization, osteoblast-to-osteocyte transition, and an anticatabolic phenotype by $\gamma$-carboxylation-dependent andindependent mechanisms. Am J Physiol Cell Physiol 6: C1358-C1367.

7. Beulens J, Bots M, Atsma F, Bartelink M, Prokop M, et al. (2009) High dietary menaquinone intake is associated with reduced coronary calcification. Atherosclerosis 2: 489-493.

8. Sato T, Yamada Y, Ohtani Y, Mitsui N, Murasawa H, et al. (2001) Production of menaquinone (vitamin K 2)-7 by Bacillus subtilis. J Biosci Bioeng 1: 16-20.

9. Sato Y, Honda Y, Kaji M, Asoh T, Hosokawa K, et al. (2002) Amelioration of osteoporosis by menatetrenone in elderly female Parkinson's disease patients with vitamin D deficiency. Bone 1: 114-118.

10. Shearer M, Newman P (2008) Metabolism and cell biology of vitamin K. Thromb Haemost 4: 530-547.

11. Hu H, Yao S, Mei L, Zhu Z, Hur B (2000) Partial purification of nattokinase from Bacillus subtilis by expanded bed adsorption. Biotechnol Lett 17: 1383-1387.

12. Chung H (1999) Volatile Components in Fermented Soybean (Glycine max) Curds. J Agric Food Chem 47: 2690-2696.

13. Shabir G (2010) Development and validation of a stability-indicating LC method for the determination of domperidone, sorbic acid, and propylparaben in pharmaceutical formulations. J Liq Chromatogr Relat Technol 20:1802-1813.

14. Kamao M, Suhara Y, Tsugawa N, Uwano M, Yamaguchi N, et al. (2007) Vitamin $\mathrm{K}$ content of foods and dietary vitamin $\mathrm{K}$ intake in Japanese young women. J Nutr Sci Vitaminol 6: 464-470. 